\title{
PROTEUS SYNDROME
}

Gaurav Agrawal', Madhu Mathur², Usha Acharya 3 , Ashwani K. Mathur 4

${ }_{1}^{1}{ }^{\text {rd }}$ Year, Resident Doctors, Department of Paediatrics, Mahatma Gandhi Medical College and Hospital, Sitapura, Jaipur.

2Professor, Department of Paediatrics, Mahatma Gandhi Medical College and Hospital, Sitapura, Jaipur.

3 Professor, Department of Paediatrics, Mahatma Gandhi Medical College and Hospital, Sitapura, Jaipur.

${ }_{4}^{4}$ Professor, Department of Orthopaedics, Mahatma Gandhi Medical College and Hospital, Sitapura, Jaipur.

\section{ABSTRACT}

\section{BACKGROUND}

Proteus syndrome is a rare disorder of patchy/mosaic postnatal overgrowth.

\section{Case Characteristics}

Patient presented with hemihypertrophy, hyperpigmented vascular and epidermal nevi, kyphoscoliosis, macrodactyly, lipoma, limb length inequality.

\section{INTERVENTION}

Correction of limb-length inequality suggested but declined.

\section{MESSAGE}

Diagnosis is difficult and entirely clinical. Management palliative only.

\section{KEYWORDS}

Vascular Malformations, Macrodactyly, Hemihypertrophy, Pigmented Nevi, Asymmetric Overgrowth.

HOW TO CITE THIS ARTICLE: Agrawal G, Mathur M, Acharya U, et al. Proteus syndrome. J. Evolution Med. Dent. Sci. 2016;5(32): 1771-1774, DOI: $10.14260 /$ jemds/2016/417

\section{CASE REPORT}

A 10-year-old patient presented with chief complaint of hypertrophy of various parts of the body, mainly involving left side of limbs and trunk.

These overgrowths in body, which developed later to deformities were first noticed by parents when patient was of around one year of age. Since then these growths were progressively increasing in size. Also there was complaint of hyperpigmentation involving many parts of the body.

The obstetric history was apparently normal. There was no history of consanguinity. According to history provided by parents and birth record, he showed no obvious congenital deformities. The family history was negative/not significant. Both parents and two siblings showed no evidence of the disease. On examination, facial asymmetry was present. Face was long with large eyes.

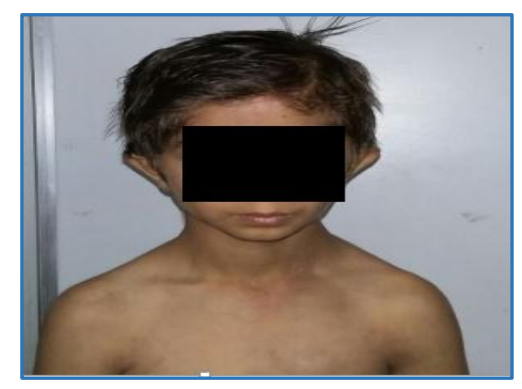

Fig. 1: Facial Asymmetry, Long Face, Large Eyes

Financial or Other, Competing Interest: None.

Submission 07-01-2016, Peer Review 25-02-2016,

Acceptance 01-03-2016, Published 21-04-2016.

Corresponding Author:

Dr. Gaurav Agrawal,

74 B, Jawahar Nagar Colony,

Near Glass Factory, Tonk Road,

Jaipur-302018,

Rajasthan.

E-mail: gauravagwl@yahoo.com

DOI: $10.14260 / \mathrm{jemds} / 2016 / 417$
He was having normal height and head circumference for age. He was of normal intelligence. There was hemihypertrophy, which was much pronounced over left buttock and left side of pelvis.

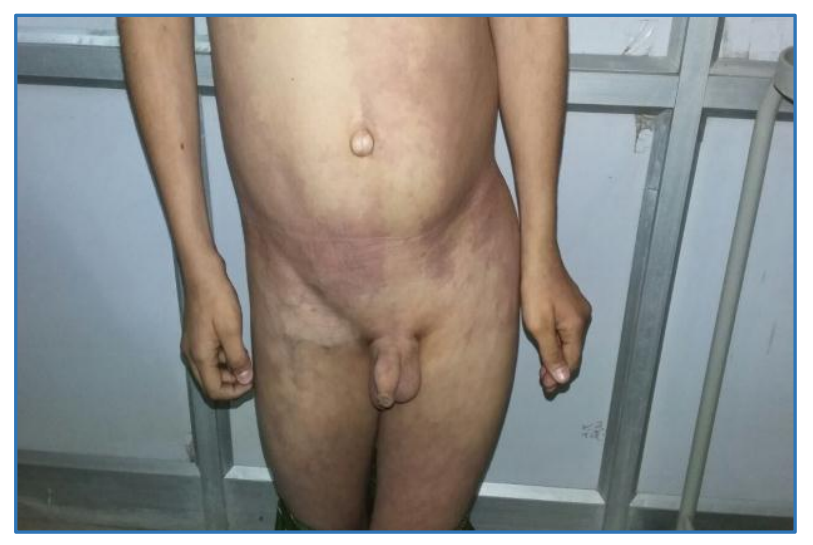

Fig. 2: Left Hemihypertrophy

Left plantar hyperplasia was present.

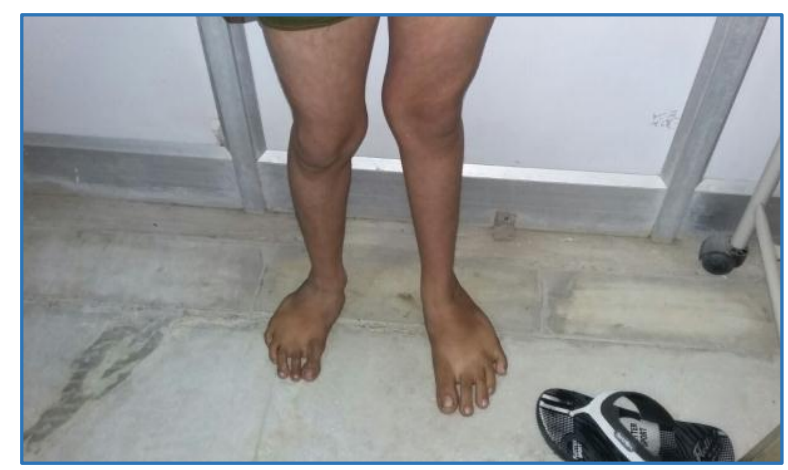

Fig. 3: Left Plantar Hyperplasia

Vascular and epidermal nevi were present over left upper limb extensor surface and lower abdominal area anteriorly extending up to thighs. 


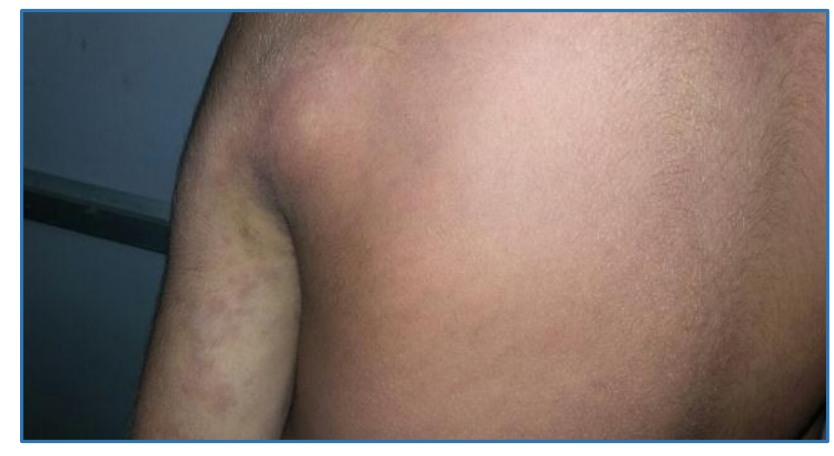

Fig. 4: Epidermal Nevi over Left Upper Limb Extensor Surface

Left leg was $1 \mathrm{~cm}$ longer than the right. Eyes were large. Asymmetric chest and abdomen were associated with kyphoscoliosis.

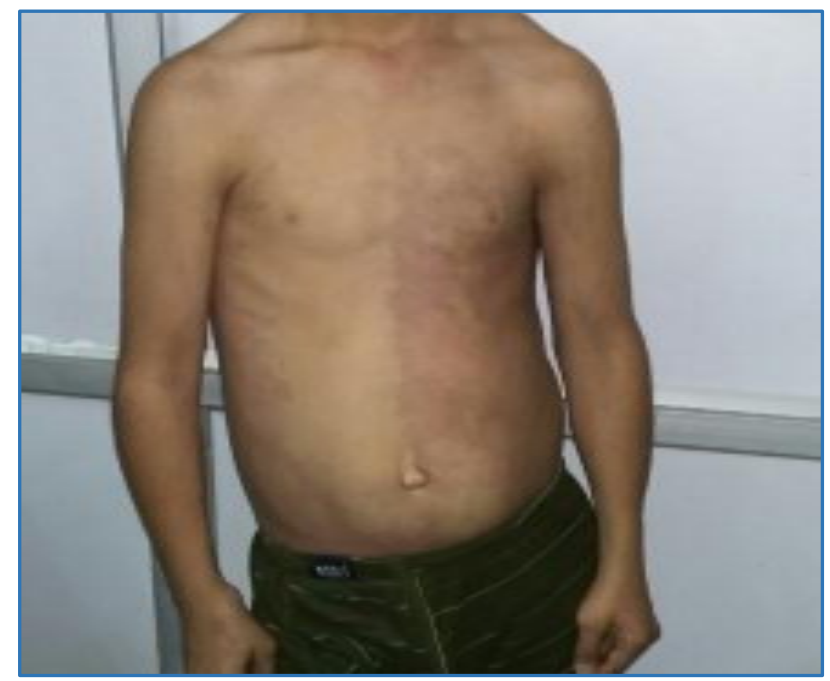

Fig. 5: Asymmetric Chest, Abdomen and Kyphoscoliosis

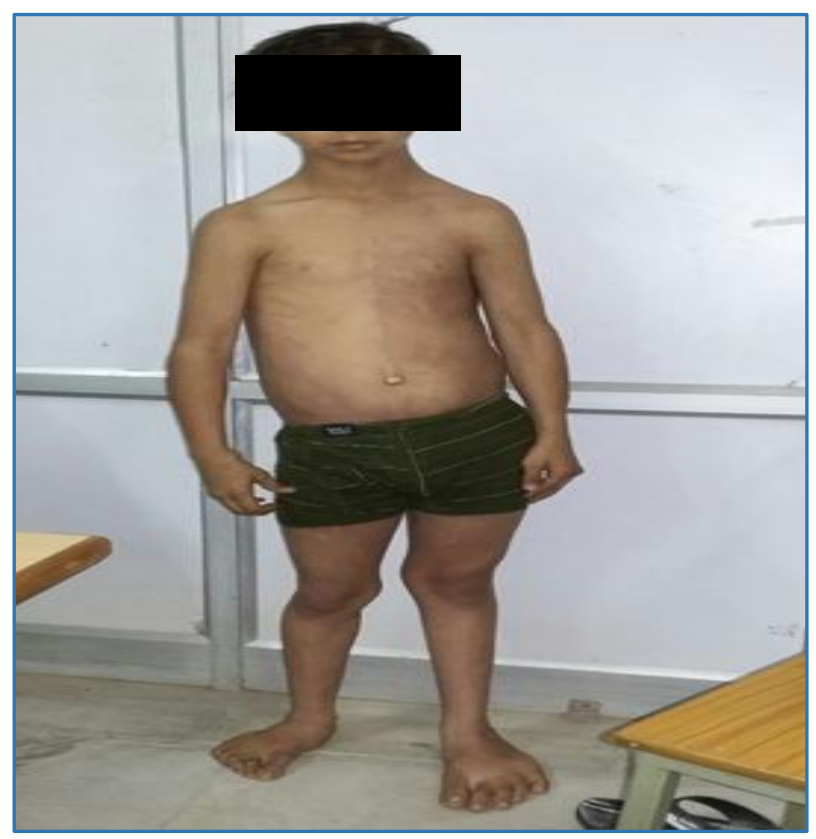

Fig. 6: Enlarged Right Hand

There was lipoma on the nape of the neck.

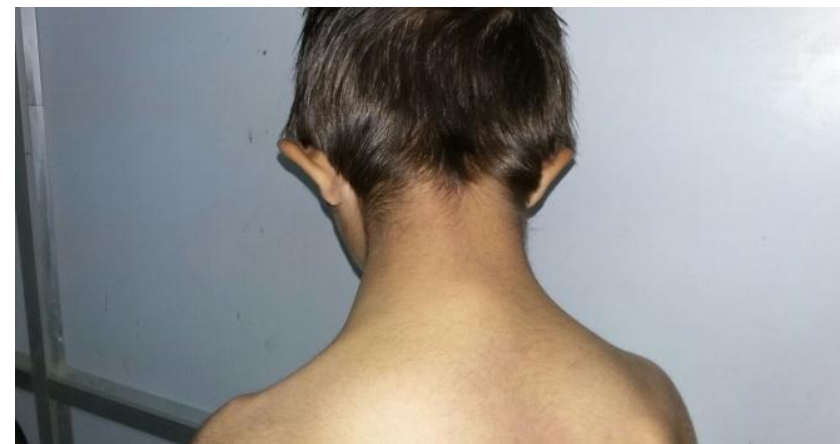

Fig. 7: Lipoma over Nape of Neck

\section{DISCUSSION}

Proteus Syndrome (PS) was described as a discrete clinical entity in $1979 . .^{1}$ and assigned its name several years later.1,2 This is a relatively recently delineated syndrome, probably because it is so rare and overlaps with number of other asymmetric overgrowth syndromes.

This disorder is characterized by such striking and varied deformities that Wiedemann and Associates called it Proteus Syndrome after Greek god Proteus (Meaning "polymorphous") who was capable of transforming into any shape to disguise himself and thus escape from his enemies. (Wiedemann and Associates felt that this syndrome was capable of doing same thing to prevent its detection as a specific disorder).$^{3}$

The oldest known case of PS was that of Mr. Joseph Merrick, described by Treves in the 19th Century.,5 The rarity of PS contributes to confusion and controversy regarding the disorder, especially regarding the diagnosis.

\section{Manifestations}

The clinical features are truly protean in their variety, severity and combinations. The primary clinical features are macrodactyly, hemihypertrophy, pigmented nevi, subcutaneous tumours (Mostly lymphangiomas) and axial skeletal anomolies. ${ }^{3}$

The manifestations are typically asymmetric and the location of the manifestations varies remarkably among the patients.

Symmetric pattern (e.g., overgrowth of both hands and both feet) should lead one to doubt the diagnosis of PS, as this is rare in confirmed cases.

The second general feature of PS is that it is rapidly progressive and typically occurs at frighteningly rapid pace.

The overgrowth typically affects bone underlying the enlarged body part in a remarkably irregular fashion causing the body part and the underlying bone to lose its normal architecture. Hallmark of the disorder is that the affected bones can become distorted. Vascular malformations occur as cutaneous capillary malformations.6,7 Patients are described as having 'lipomas,' but these are actually localized overgrowth of fatty tissue.

Another common skin manifestation in PS is the linear verrucous epidermal nevus. Slowly evolving Cerebriform Connective Tissue Nevus (CCTN) is also reported. Few patients present facial phenotype of PS. This phenotype comprises down slanting palpebral fissures, flattening of the malar bones, relative lengthening of the face and a persistently open mouth. 


\section{DIAGNOSIS}

\begin{tabular}{|l|l|}
\hline $\begin{array}{c}\text { To make a diagnosis of PS, one must have all the general } \\
\text { criteria and various specific criteria }\end{array}$ \\
\hline General Criteria & Specific Criteria \\
\hline All of the following: & Either: \\
\hline Mosaic distribution of lesions & Category A or, \\
\hline Sporadic occurrence & Two from category B or, \\
\hline Progressive course & Three from category C \\
\hline \multicolumn{2}{|c|}{ Table.8,9,10 of Revised PS diagnostic criteria } \\
\hline
\end{tabular}

\section{Specific Criteria Categories}

A. 1. Cerebriform connective tissue nevus.

B. 1. Linear epidermal nevus.

2. Asymmetric, disproportionate overgrowth of-

\section{One or more}
(a) Limbs.
(b) Hyperostosis of the skull.
(c) Hyperostosis of the external auditory canal.
(d) Megaspondylodysplasia.
(e) Viscera.

\section{Spleen/Thymus}

3. Specific tumours before 2 nd decade.

\section{One of the following:}

(a) Bilateral ovarian cystadenoma.

(b) Parotid monomorphic adenoma.

C 1. Dysregulated adipose tissue either one.
(a) Lipomas.
(b) Regional lipohypoplasia.

2. Vascular malformations.

\section{One or more}

(a) Capillary malformation.

(b) Venous malformation.

(c) Lymphatic malformation.

3. Lung cysts.

4. Facial phenotype.

\section{All}

(a) Dolichocephaly.

(b) Long face.

(c) Down slanting palpebral fissure.

(d) Low nasal bridge.

(e) Wide or anteverted nares.

(f) Open mouth at rest have

The case presented here has all the general criteria, i.e. mosaic distribution of lesions, sporadic occurrence and progressive course along with two from category $B$, i.e.

1. Linear epidermal nevus.

2. Asymmetric, disproportionate overgrowth.

\section{And Three from Category C, i.e.}

1. Dysregulated adipose tissue (Lipomas).

2. Facial phenotype (Long face).

3. Vascular malformations (Venous malformations).
So according to the above table of diagnosis, this case was strongly diagnosed as Proteus Syndrome as it was satisfying more than the required number of criteria.

The another table for diagnosis. ${ }^{11}$ is given below. ${ }^{11}$

Rating Scale for the Diagnosis of Proteus Syndrome.

\begin{tabular}{|l|c|}
\hline Clinical Feature & Points \\
\hline Macrodactyly, Hemihypertrophy or both & 5.0 \\
\hline Thickening of Skin & 4.0 \\
\hline Lipomas and Subcutaneous Tumours & 4.0 \\
\hline Verrucous Epidermal Nevus & 3.0 \\
\hline Macrocephaly, Buckelshadel or both & 2.5 \\
\hline Other minor abnormalities & 1.0 \\
\hline
\end{tabular}

Definitive diagnosis $>13$ points_questionable diagnosis, 10 to 13 points, diagnosis excluded $<10$ points.

This case satisfies the criteria,

Patient here was having score 17.0 (see Table below)

\begin{tabular}{|l|c|}
\hline Macrodactyly, Hemihypertrophy or both & 5.0 \\
\hline Thickening of Skin & 4.0 \\
\hline Lipomas and Subcutaneous Tumours & 4.0 \\
\hline Verrucous Epidermal Nevus & 3.0 \\
\hline $\begin{array}{l}\text { Other abnormalities } \\
\text { (Plantar Hyperplasia, Long Face) }\end{array}$ & 1.0 \\
\hline \multicolumn{1}{|c|}{ Total } & $\mathbf{1 7 . 0}$ \\
\hline
\end{tabular}

Whereas the required is only $>13.0$ for definitive diagnosis.

\section{Management}

The management of patients with PS is challenging. ${ }^{12}$ Treatment of genu valgum by osteotomy in skeletally immature patients frequently results in recurrence of deformity.

Limb length inequality has been managed by shortening osteotomies or epiphysiodesis. Scoliosis does not seem to respond to bracing, and instrumentation and bracing may be required, even with fusion however deformities can progress. ${ }^{3}$

\section{REFERENCES}

1. Cohen Jr MM, Hyden PW. A newly recognized hamartomatous syndrome. Birth Defects Orig Artic Ser 1979;15:291-6.

2. Wiedemann HR, Burgio GR, Aldenhoff $\mathrm{P}$, et al. The proteus syndrome. Partial gigantism of the hands and/or feet, nevi, hemihypertrophy, subcutaneous tumors, macrocephaly or other skull anomalies and possible accelerated growth and visceral infections. Eur J pediatr 1983;140:5-12.

3. Herring John Antony. Tachdjin's pediatric orthopedics, texas scottish rite hospital for children. proteus syndrome 2008;4:1897-9.

4. Cohen Jr MM. The elephant man did not have neurofibromatosis. Proc Greenwood Genet Center 1987;6:187-92.

5. Treves F. A case of congenital deformity. Proc pathol soc London 1885;36:494-8. 
6. Nguyen D, Turner JT, Oslen C, et al. Cutaneous manifestations of proteus syndrome: correlations with general clinical severity. Arch Dermatol 2004;140:94753.

7. Twede JV, Turner JT, Biesecker LG, et al. Evolution of skin lesions in proteus syndrome. J Am Acad Dermatol 2005;52:834-8.

8. Biesecker LG, Happle R, Mulliken JB, et al. Proteus syndrome: diagnostic criteria, differential diagnosis, and patient evaluation. Am J Med Genet 1999;84:389-95.
9. Turner JT, Cohen Jr MM, Biesecker LG. Reassessment of proteus syndrome literature: application of diagnostic criteria to published cases. Am J Med Genet 2004;130A:111-22.

10. Cohen Jr MM. Proteus syndrome: an update. Am J Med Genet C Semin Med Genet 2005;137:38-52.

11. Stricker S. Musculoskeletal manifestations of proteus syndrome: report of two cases with literature review. J pediatr Orthop 1992;12(5):667-74.

12. Biesecker LG. Proteus syndrome in Cassidy SB, Allanson J, eds. Management of genetic syndromes hoboken, John willy and sons, Inc. 2005;1:449-56. 